\title{
The Impact of Tax Structure on Residents' Consumption in China
}

\author{
Ying $\mathrm{Li}^{*}$ \\ The United Front Work Department \\ Yunnan University of Finance and Economics \\ Kunming, China \\ 705515930@qq.com
}

\author{
Yuan Li \\ International Business School \\ Yunnan University of Finance and Economics \\ Kunming, China \\ 879519254@qq.com
}

\begin{abstract}
The author refers to the research methods of the existing literature, combined with the availability and manageability of the data, selects the panel data in China in the last 13 years from government statistics to study this topic. The results of model test show that per capital commodity tax has a significant negative impact on residents' consumption, per capital personal income tax and social public service level have no significant negative impact on residents' consumption, per capital property tax and per capital disposable income have a significant positive impact on residents' consumption. At the end, the author puts forward some tax policy recommendations to promote residents' consumption demand.
\end{abstract}

Keywords: tax structure, residents' consumption, empirical test

\section{INTRODUCTION}

From 2005 to 2017, China's economy continued to grow. However, behind the rapid economic development, there are still several problems in Chinese residents' consumption. First of all, the consumption rate of residents (the proportion of total consumption to GDP) is seriously low. Second, the growth rate of Chinese residents' consumption is lower than the growth rate of GDP. Third, the growth rate of Chinese residents' consumption is lower than that of government consumption. Fourthly, the growth rate of Chinese residents' consumption is lower than that of residents' savings. The current situation of China's resident consumption shows that the resident consumption is insufficient. In order to give full play to the role of resident consumption in promoting economic growth, how to expand Chinese resident consumption has become a new problem in China's economic development.

The academic community has conducted in-depth and extensive research on the issue of stimulating household consumption from the perspective of taxation.Fan Yuxia (2011) analyzed the impact of China's taxation system on household consumption, pointing out that taxation system innovation is an important driving mechanism to promote the growth of household consumption [1].Li Xiangju, Zhao Lanbing and Zhao Bo (2015) explored the impact of taxation on the consumption level and consumption structure of urban and rural residents in China by establishing an inter-provincial panel data model and a cointegration model[2].Zhang Xiaolin and Qi Gongyuan (2010) started with the empirical analysis of the main income tax and auxiliary tax to regulate the income distribution of residents, and analyzed the relationship between the main tax types and the consumption of residents, and proposed the tax structure structure to promote the consumption of residents [3]. Chu Deyin and Yan Wei (2012) empirically estimate the structural effects of tax policies on consumer demand through dynamic panel data model and GMM estimation method [4].

By combing the existing literature, it is known that the current academic circles have studied the changes in consumer demand at the tax burden, tax policy, single tax type or tax system level, but few scholars analyze its impact on household consumption from the perspective of tax structure. . Therefore, based on the analysis of the theoretical effects of taxation on household consumption, this paper explores the relationship between tax structure and household consumption as a supplement and expansion of research in this field.

\section{Methodology}

Since this topic mainly studies the impact of China's tax structure on residents' consumption, tax is the main source of government revenue, and it is impossible to collect data on different taxes through direct interviews and questionnaires. The consumption structure of residents is very complicated, and it is impossible to directly investigate the consumption expenditure of residents in different regions of China in a limited time. Therefore, based on the particularity of the research topic, the author chose to use the data of government statistics from 2005 to 2017 to carry out the research on this topic.

\section{A. Main variables}

In order to study the impact of different taxes on residents' consumption under the tax structure, the six main variables designed by the author for panel data testing are as follows:

The specific representation and calculation method of each variable used in the empirical analysis model of this dissertation is shown in Table 1: 
TABLE 1 METH OD OF CACULATING VARIABLES

\begin{tabular}{|c|c|c|c|}
\hline Variable Type & Variable Name & $\begin{array}{l}\text { Variable } \\
\text { Symbol }\end{array}$ & Calculation Method \\
\hline \multirow[t]{2}{*}{$\begin{array}{c}\text { Explained } \\
\text { variable }\end{array}$} & $\begin{array}{l}\text { Per capita consumption } \\
\text { expenditure of } \\
\text { residents }\end{array}$ & $\mathrm{y}$ & $\begin{array}{l}\text { Total Consumption Expenditure of Regional Residents/ Regional } \\
\text { End-of-Year Population }\end{array}$ \\
\hline & $\begin{array}{l}\text { Per capita commodity } \\
\qquad \operatorname{tax}\end{array}$ & $x_{1}$ & (Regional VAT+Business Tax)/Regional End-of-Year Population \\
\hline \multirow[t]{3}{*}{$\begin{array}{l}\text { Explanatory } \\
\text { variables }\end{array}$} & $\begin{array}{l}\text { Per capita personal } \\
\text { income tax }\end{array}$ & $x_{2}$ & Regional personal income tax / Regional End-of-Year Population \\
\hline & Per capita property tax & $x_{3}$ & $\begin{array}{l}\text { (Regional Real Estate Tax + Urban Land Use Tax + Vehicle and Ship } \\
\text { Tax + Land Value Added Tax + Contract Tax) / Regional End-of-Year } \\
\text { Population }\end{array}$ \\
\hline & $\begin{array}{l}\text { Per capita disposable } \\
\text { income }\end{array}$ & $z_{1}$ & $\begin{array}{l}\text { (Regional urban per capita disposable income } \times \text { regional end-of-year } \\
\text { urban population }+ \text { regional rural per capita net income } \times \text { regional } \\
\text { end-of-year rural population) } / \text { Regional End-of-Year Population }\end{array}$ \\
\hline Control variables & $\begin{array}{l}\text { The Level of Social } \\
\text { Public Service }\end{array}$ & $z_{2}$ & $\begin{array}{l}\text { (Regional Social Security Expenditure }+ \text { Health Expenditure + } \\
\text { Education Expenditure) / Regional Total Financial Expenditure }\end{array}$ \\
\hline
\end{tabular}

\section{B. Hypothesis}

Although different scholars have different empirical results on the impact of China's tax structure on residents' consumption, based on theoretical research, it is found that commodity tax will transfer tax burden to consumers by raising commodity prices, personal income tax will affect residents' consumption by reducing residents' disposable income. Property tax increases the current consumption of residents by increasing the cost of property held by residents. The author puts forward the following hypotheses on the relationship between tax structure and residents' consumption in China:

H1 : Commodity tax has a significant negative impact on residents' consumption.

$\mathrm{H} 2$ : Personal income tax has a significant negative impact on residents' consumption.

H3: Property tax has a significant positive impact on residents' consumption. Units

\section{Data Sources}

Data on tax related to business tax, value-added tax, consumption tax, personal income tax, property tax, and urban land use tax are obtained by inquiring the fiscal revenue data published in China Tax Yearbook from 2006 to 2018. Data comes from government statistics, so it is effective and reliable, but the absence of statistical data will have an impact on the validity of data.

Data on household consumption expenditure, per capital disposable income of urban and rural residents, population at the end of the year in urban and rural areas, social security expenditure, education expenditure, medical and health expenditure, and total regional financial expenditure are obtained by inquiring the data published in China Statistical Yearbook from 2006 to 2018. Data comes from government statistics, so it is effective and reliable, but the absence of statistical data will have an impact on the validity of data.

\section{DATA DESCRIPTION}

The third chapter proposes a methodology to study the tax structure and examine the impact of different tax types on residents' consumption. Based on this research methodology, the author collects and processes the relevant data and describes the relevant characteristics of these data. This chapter mainly includes the main characteristics of China's tax structure, the data characteristics of the main variables that need to be tested by the panel data model, the statistical description of variables and limitations.

\section{A. Statistical Description of Variables}

TABle 2 Statistical Description of VARiables

\begin{tabular}{cccccc}
\hline Variable & Obs & Mean & Std. Dev. & Min & Max \\
\hline $\mathrm{y}$ & 377 & 13610.49 & 8791.362 & 3297.77 & 53639.78 \\
$x_{1}$ & 377 & 1638.27 & 1647.414 & 251.79 & 10175.31 \\
$x_{2}$ & 377 & 218.4663 & 395.5222 & 22.73 & 2962.69 \\
$x_{3}$ & 377 & 628.9359 & 643.4823 & 33.23 & 3879.28 \\
$z_{1}$ & 377 & 15596.66 & 9339.537 & 3562.41 & 58988 \\
$z_{2}$ & 377 & 0.34821960 .0522631 & 0.1866 & 0.4765 \\
\hline
\end{tabular}

As can be seen from the table 2, among the selected samples, the national average per capital consumption expenditure of residents is 13,610.49 Yuan. The economic development level of different regions is different, and the consumption level of residents is also different. Due to the imbalance of regional development, the difference in consumption levels of Chinese residents is higher. Also it is shows that the main source of tax burden for Chinese residents is commodity tax. The disparity of per capital disposable income is also reflected in the regional per capital consumption expenditure. The imbalance in regional development has also caused a large difference in regional public service levels.

\section{DATA ANALYSIS}

In order to test whether there is a highly correlated phenomenon between variables, it is necessary to analyze the correlation of the variables in order to determine whether the results of the model have serious multi-collinearity problems. The correlation analysis results of each variable are shown in Table 3:

TABLE 3 VARIABLE CORRELATION COEFFICIENT MATRIX
\begin{tabular}{lcccccc}
\hline $\mathrm{y}$ & $x_{1}$ & $x_{2}$ & $x_{3}$ & $z_{1}$ & $z_{2}$ \\
\hline $\mathrm{y}$ & 1.0000 & & & & \\
$x_{1}$ & -0.0396 & 1.0000 & & & & \\
$x_{2}$ & 0.2308 & -0.4315 & 1.0000 & & & \\
$x_{3}$ & -0.3432 & -0.3928 & -0.3137 & 1.0000 & & \\
$z_{1}$ & 0.9851 & 0.0575 & 0.1861 & -0.3191 & 1.0000 & \\
$z_{2}$ & 0.0545 & -0.1584 & -0.1765 & -0.0128 & 0.0923 & 1.0000 \\
\hline
\end{tabular}

From the correlation coefficient matrix of the variables in table 3 , it can be seen that the correlation coefficient between the explained variable and the control variable is as high as 0.9851 , but consumption is a function of income, the high correlation between the two variables is normal. The absolute value of correlation coefficient between other variables is not high. From this, it can be firstly judged that there is no serious multi-collinearity problem between variables. 


\section{A. Building Models and Hypothesis Testing}

From the above analysis, in theory, there is a relationship between tax and residents' consumption. In order to test the impact of different taxes on the consumption level of residents in China, the panel data model designed in this dissertation is as follows:

$$
y_{i t}=\alpha_{0}+\alpha_{1} X_{i t}+\beta Z_{i t}+\varsigma_{i}+\mu_{i t}
$$

Among them, is the per capital consumption expenditure of residents in the -th year of the -th province; is a set of explanatory variables, indicating the sample data of the -th year of the -th province, mainly including per capital commodity tax , per capital personal income tax , per capital Property tax ; is a set of control variables, representing the sample data of the -th year of the -th province, mainly including the per capital disposable income and the level of social public service . represents a cross-sectional (regional) fixed effect that does not change over time; represents a random error term that is independent of the explanatory variable. The subscript $(=1,2, \ldots, 29)$ represents a sample of 29 provinces in China, and the subscript $(=2005, \ldots, 2017)$ indicates the time period of the investigation.

Before the regression of the panel data, Hausman test is used to determine whether the fixed effect model or the random effect model should be used in data analysis. Because the sample selected in this paper contains almost all provinces in China, the sample is close to the whole, it can be primarily judged that the fixed effect model should be chosen. The results of Hausman test are shown in Table 4. Chi2(3)=7.52, Prob $>$ chi $2=0.0559$, less than 0.1 . Therefore, the model has a fixed effect. Next, the author will use the fixed effect model to test the panel data.

TABLE 4 HAUSMAN TEST RESULTS

\begin{tabular}{|c|c|c|c|c|}
\hline \multicolumn{2}{|r|}{ (b) } & e(B) & \multicolumn{2}{|c|}{ re (b-B) Difference sqrt(diag(V_b-V_B)) S.E. } \\
\hline$x_{1}$ & -0.47312 & 0.0072554 & -0.4803754 & 0.1733033 \\
\hline$x_{2}$ & -0.5688353 & -0.6315204 & 0.0626851 & 0.1749457 \\
\hline$x_{3}$ & 1.987324 & 1.465179 & 0.5221447 & 0.2328157 \\
\hline$z_{1}$ & 0.8625475 & 0.8527006 & 0.009847 & 0.0112045 \\
\hline$z_{2}$ & -1422.737 & -2861.479 & 1438.743 & 673.1683 \\
\hline \multicolumn{3}{|c|}{$\operatorname{chi} 2(3)=7.57$} & \multicolumn{2}{|c|}{ Prob $>$ chi2 $=0.0559$} \\
\hline
\end{tabular}

\section{B. Fixed Effect Model Test of Panel Data}

According to the research needs, this paper obtains the following five econometric models through the stepwise regression method:

The model (1) studies the impact of per capital commodity tax on residents' consumption when only introducing per capital commodity tax $\left({ }^{x_{1}}\right)$. Model (2) is based on model (1), when introducing per capital personal income tax $\left(x_{2}\right)$, to study the impact of per capital commodity tax and per capital income tax on residents' consumption. Model (3) is based on model (2), when introducing per capital property tax $\left({ }^{x_{3}}\right)$, to study the impact of three taxes on household consumption. Model (4) is based on model (3), after introducing the control variable of per capital disposable income $\left({ }^{z_{1}}\right)$, to study the impact of three kinds of taxes on residents' consumption. The model (5) studies the effects of three different taxes on residents' consumption behavior under the condition of controlling the per capital disposable income $\left({ }^{z_{1}}\right)$ and the level of social public service ( $z_{2}$ ), which is the model closest to the real economic living conditions. Table 5 shows the estimated results of the relevant models.

Table 5 Estimation results of fixed-effect models

\begin{tabular}{cccccc}
\hline \multicolumn{5}{c}{ Explained variables: per capita consumption expenditure (y) } \\
\hline Explanatory variables & $(1)$ & $(2)$ & $(3)$ & $(4)$ & $(5)$ \\
$x_{1}$ & $7.519094^{* *}$ & $7.397475^{* *}$ & $2.412206^{* *}$ & $-0.4770788^{*}$ & $-0.47312^{*}$ \\
$x_{2}$ & & 0.5901765 & $-1.792419^{*}$ & -0.4797925 & -0.5688353 \\
$x_{3}$ & & & $10.19938^{* *}$ & $2.043829 * *$ & $1.987324^{* *}$ \\
Control variables & & & & & \\
$z_{1}$ & & & & $0.8525166^{* *}$ & $0.8625475^{* *}$ \\
$z_{2}$ & & & & & -1422.7370 \\
cons & 1292.181 & 1362.491 & 3635.469 & -84.9615 & 302.52 \\
R-square & 0.7885 & 0.7877 & 0.886 & 0.9683 & 0.9689 \\
F & 1355.49 & 676.3 & 727.35 & 2288.34 & 1828.51 \\
N & 377 & 377 & 377 & 377 & 377 \\
\hline
\end{tabular}

Notes: * indicates significant at $10 \%$ level, ** indicates significant at $5 \%$ level

\section{Analysis of Empirical Results}

In models (1)-(3), the per capital commodity tax is positively correlated with the per capital consumption expenditure of residents and the coefficients are significant at a significant level of 5\%. After adding the control variables, the R-square of models (4) and (5) are higher than those of the first three models, indicating that model (4) and model (5) are more effective than the first three models, and the interpretation results are more stable. At this time, the coefficient of per capital commodity tax is negative, which is significant at the significant level of $10 \%$, which indicates that the increase in per capital commodity tax will curb the growth of per capital consumption expenditure of residents.

In the model (2), the per capital personal income tax has no significant positive impact on per capital consumption expenditure. The results of model (3) show that per capital personal income tax has a significant negative impact on per capital consumption expenditure at a significant level of $10 \%$. In model (4) - (5), per capital personal income tax has no significant negative impact on per capital consumption expenditure. This shows that under different conditions, per capital personal income tax will have a positive or negative impact on residents' consumption. 
The results of model (3) - (5) show that per capital property tax has a significant positive impact on per capital consumption expenditure, and the coefficients are significant at a significant level of 5\%. This shows that the impact of per capital property tax on residents' consumption is relatively stable.

The test results of model (4) - (5) show that the per capital disposable income of residents has a significant positive impact on the per capital consumption expenditure at a significant level of $5 \%$, that is, the growth of per capital disposable income of residents will promote the growth of per capital consumption expenditure of residents. On the contrary, the growth of the level of social public services has no significant negative impact on the growth of per capital consumption expenditure.

The goodness of fit of the model (5) reached 0.9689 in the test of stepwise regression, and the change of the explained variable can be basically explained by the explanatory variable and the control variable. Secondly, the model's Prob $>F=0.000$, the model is jointly significant at the $1 \%$ significance level, which also shows that the model has a good explanatory power Model (5) has the highest goodness of fit and is closest to real economic living conditions. Therefore, the estimation result of model (5) is the final conclusion of this research. Table 6 shows the expansion of the test results of model (5):

Table 6 Estimation results of model (5)

\begin{tabular}{ccccccc}
\hline $\mathrm{y}$ & Coef. & Std. Err. & $\mathrm{t}$ & $\mathrm{P}>\mathrm{t}$ & $95 \%$ Conf. & Interval \\
\hline$x_{1}$ & -0.4731 & 0.2610 & -1.81 & 0.0710 & -0.9865 & 0.0403 \\
$x_{2}$ & -0.5688 & 0.5719 & -0.99 & 0.3210 & -1.6937 & 0.5561 \\
$x_{3}$ & 1.9873 & 0.4886 & 4.07 & 0.0000 & 1.0263 & 2.9484 \\
$z_{1}$ & 0.8625 & 0.0307 & 28.14 & 0.0000 & 0.8023 & 0.9228 \\
$z_{2}$ & -1422.73701879 .6780 & -0.76 & 0.4500 & -5119.88302274 .4100 \\
cons 302.5200 & 559.6688 & 0.54 & 0.5890 & -798.2949 & 1403.3350 \\
\multicolumn{5}{c}{ R-square $=0.9689$} & $\mathrm{~F}(5,343)=1828.51$ & Prob $>\mathrm{F}=0.000$ \\
\hline
\end{tabular}

From the results of model (5), the coefficient of per capital commodity tax $\left({ }^{x_{1}}\right)$ is negative, prob $>\mathrm{t}=0.0710<0.1$, which indicates that the per capital commodity tax is significantly negatively correlated with residents' consumption and is significant at the significant level of $10 \%$. For every 1 Yuan increase in per capital commodity tax, the per capital consumption expenditure of residents will decrease by 0.47 Yuan. The high proportion of commodity tax in China will restrain the consumption demand of residents, hypothesis $x_{1}$ can be proved. At present, China's tax structure with commodity tax as the main body hinders the growth of residents' consumption. As mentioned in the literature review, the commodity tax transfers the tax burden to consumers in the form of raising commodity prices, which increases the consumption cost of residents. Because of the "income effect" of tax, consumers will reduce consumption expenditure; under the influence of the "substitution effect", consumers will choose other cheaper consumer goods or tend to save rather than consume.

The coefficient of per capital personal income tax $\left(x_{2}\right)$ is negative, prob $>\mathrm{t}=0.3210>0.1$. The coefficient is not significant. There is no significant negative relationship between per capital personal income tax and per capital consumption expenditure. Hypothesis $\mathrm{H}_{2}$ is unprovable. Obviously, China's marginalized personal income tax has not significantly reduced the disposable income of residents, thus having an insignificant negative impact on consumer demand. Progressive income tax can also improve the average propensity to consume of the whole society by correcting the unfair income distribution and narrowing the income gap, thus offsetting the negative income effect of income tax on residents' consumption demand to a certain extent. Secondly, Gong (2001) pointed out that the tax awareness of Chinese residents is not strong, the level of government collection and management is limited, the range of income covered by personal income tax is relatively narrow, and the collection rate is relatively low. Although the absolute amount of personal income tax keeps increasing, the amount is still very small relative to the population of Chinese residents, so the role of personal income tax is limited.

Per capital property tax $\left(x_{3}\right)$ is positively correlated with household consumption and the correlation coefficient is significant at the level of $5 \%$. The per capital property tax increases by 1 Yuan, and the per capital consumption expenditure will increase by 1.987 Yuan, hypothesis $H_{3}$ can be proved. This shows that the property tax imposed by the government can produce a strong substitution effect between current consumption and future consumption (current savings). Property tax reduces the future income of current savings, that is, the utility of current savings is less than that of current consumption. Consumers prefer current consumption rather than holding property. This may be related to current imperfect property tax system, narrow tax base and low property tax rate in China.

From the perspective of control variables, at a significant level of $5 \%$, per capital disposable income ( $\left.z_{1}\right)$ has a significant positive effect on per capital consumption expenditure. The per capital disposable income increases by 1 Yuan, and the per capital consumption expenditure increases by 0.863 Yuan. This also proves that the disposable income of residents is an important factor affecting the consumption of residents. The level of social public service $\left(z_{2}\right)$ has a negative impact on residents' consumption, but prob $>\mathrm{t}=0.45$, the coefficient is highly insignificant. The reason for this conclusion is that the cost of medical services and education in China is too high. Residents spend a large part of their income on savings to cope with possible medical and educational expenditures in the future. At the same time, with the development of China's economy and society, the problem of aging is becoming more and more serious. Social security funds are facing greater pressure, income and expenditure contradictions are more prominent, resident have to reduce consumption, increase savings to cope with the future pension problems. At present, the overall planning level of social security system is low, the coverage is narrow, and there are great differences among different industries and regions. 
Especially, rural areas have not been really included in China's social security system. The majority of rural residents can only rely on savings and the support of their children to solve the future pension problem, which will not only not increase their current consumption, but will also limit the level of consumption expenditures of future generations. This has exacerbated the current situation that the Chinese residents' savings rate is high and the consumption of residents has been fluctuated at a low level for a long time (Yang \& Wang, 2007).

\section{Summary}

Empirical results show that tax can regulate residents consumption and different taxes have different effects on residents' consumption. Under the conditions closest to real life, commodity tax has a significant negative impact on residents' consumption, which proves hypothesis . This is consistent with the theory mentioned in the literature review that the commodity tax can reduce the consumption of residents by raising the relative price of commodities. The commodity tax with a high proportion of China does hinder the growth of residents' consumption. Personal income tax has no significant negative effect on residents' consumption. Which is consistent with the theory that personal income tax can reduce residents' consumption by reducing residents' disposable income. Personal income tax with a small proportion and small amount has a limited effect on residents' consumption. But the insignificant negative effect is different from the hypothesis . Property tax has a significant positive effect on residents' consumption, which proves that hypothesis and is consistent with the theoretical analysis mentioned in the literature review.

\section{CONCLUSIONS AND RECOMMENDATIONS}

The panel data regression results show that commodity tax has a significant negative impact on residents' consumption; personal income tax has no significant negative impact on residents' consumption; property tax has a significant positive impact on residents' consumption; per capital disposable income of residents is indeed an important factor affecting residents' consumption; the improvement of the level of social public service will not only not promote the consumption of residents, but also have a negative effect on the consumption of residents. This shows that the current tax structure with commodity tax as the main body has restrained the growth of residents' consumption, and the marginalization of personal income tax has led to its effect not obvious, and the positive effect of reasonable collection of personal income tax has offset the negative effect to a certain extent.

Based on the above test results, the author believes that in order to promote the improvement of residents' consumption level and expand domestic demand, on the one hand, the government should reduce the overall tax burden in China, increase the income of residents' departments, and enhance residents' consumption capacity. On the other hand, the government should optimize the tax structure, reduce the proportion of commodity tax, increase the proportion of direct tax such as personal income tax and property tax, and enhance the ability of tax to regulate income distribution and residents' consumption. So, it is necessary to adjustment of Commodity Tax System, optimize personal income tax to regulate resident income, improve Property Tax and Increasing Residents' Consumption Tendency, levy Social Security Tax on improving residents' consumption confidence.

\section{REFERENCES}

[1] Fan Xiaxia."The effect of taxation system on consumer demand and institutional innovation," Tax Research, 2011(2).

[2] Li Xiangju, Zhao Lanbing, Zhao Bo.'The Impact of Taxation on Consumption Level and Structure of Urban and Rural Residents in China,"Tax Research, 2015(9).

[3] Zhang Xiaolin, Zhai Gongyuan."Empirical Analysis and Thinking of China's Tax System Structure and Household Consumption,"China Urban Economy, 2010(5)

[4] Chu Deyin, Yan Wei.'Tax Policy and Consumer Demand: A New Perspective Based on Structural Effect,"Economic Theory and Economic Management, 2012 (3).

[5] Avery, R. B., Elliehausen, G. E., \& Kennickell, A. B.”Changes in consumer installment debt: evidence from the 1983 and 1986 surveys of consumer finances,'Federal Reserve Bulletin(Oct), 1987,pp.761-778.

[6] Li, X. J., \& Zhou, L. Z.”Tax Policy Research on Expanding Resident Consumption in China - Empirical Analysis Based on the Impact of Tax on Consumption," Finance and Trade Economy.2013 (2), pp.18-27.

[7] Li, X. Y."Taxation system conducive to the initiation of domestic demand.,'Tax research,2010(6),pp. 17-20.

[8] Liu, R.Linkage Effect of Structural Tax Reduction in China from the Perspective of Tax System Optimization. Tax Research,2013(2).

[9] Liu, X. N.’Tax structure effect analysis. (Doctoral dissertation),"2013.

[10] Liu, Z."Empirical Analysis on the Tax Structure and Residents Consumption in the context of Structure Tax Deduction,"'(Doctoral dissertation). 2016 . 